\title{
Arterial indicator-dilution curves in aortic incompetence
}

\author{
H. M. SNOW AND P. G. F. NIXON
}

From the Department of Thoracic Surgery, General Infirmary, Leeds

In severe valvular regurgitation the presence of a regurgitant volume and the abnormalities of stroke volume, residual volume, and mixing (Phinney, Cotton, and Shillingford, 1961) distort the arterial indicator-dilution curve in a characteristic manner. The gradient of the down-slope of the primary curve is reduced (Korner and Shillingford, 1955), the peak concentration is lowered, the time components are prolonged, and the recirculation peak may disappear (Woodward, Burchell, and Wood, 1957). In patients with severe disability it appears that aortic incompetence may cause much less distortion than mitral incompetence. The purpose of this communication is to examine the evidence that bears upon this suggestion and to consider its implications.

\section{MATERIAL AND METHODS}

Six patients with severe aortic incompetence were selected for this study. Five were greatly disabled by the lesion and the sixth was in diuretic-resistant heart failure. Sinus rhythm was present in all. The diagnosis was confirmed, and aortic stenosis and mitral disease were excluded by clinical, radiological, and cardiographic examination, by rightand transseptal left-heart catheterization, and by operation in three patients, including the one with heart failure.

During the cardiac catheterization arterial indicator-dilution curves were recorded from the right ear with the Cambridge photo-electric apparatus after Coomassie blue dye had been injected into the left atrium close to the fossa ovalis during a period of two seconds. The technique of heart catheterization differed from the method previously described (Nixon, 1960) in that a catheter was introduced percutaneously into the aorta and the Braunwald test (Braunwald and Morrow, 1958) for the assessment of aortic regurgitation was performed. The ratio of least concentration to recirculation peak concentration (CL/CR, Wood and Woodward, 1957) was calculated directly from the ear-piece dilution curve obtained by injecting dye into the left atrium. The gradient of the down-slope of the curve of primary circulation, the mean circulation time, and the cardiac output were calculated in the manner previously described (Nixon and Snow, 1962).

The area of the left atrial shadow on six-foot penetrated chest radiograms was measured with a planimeter.

The results of the investigations were compared with the findings obtained by similar techniques in the cases of mitral incompetence that have been reported by the authors (Nixon and Snow, 1962).

\section{RESULTS}

The aortic regurgitation was considered to be severe because the symptoms caused great disability, the pulse was collapsing, and the carotid arterial pulsation was prominent. The arterial blood pressures measured $150 / 35,150 / 45,170 / 50$, $140 / 15$, and $140 / 30$. The Braunwald test showed that the dye regurgitated into the left ventricle or ascending aorta when it was injected into the aorta below the diaphragm. During the Braunwald test the heart rates lay between 60 and 80 per minute, except in the patient with heart failure where the rate was $120 /$ minute. The right ventricular or pulmonary arterial systolic pressures lay between

\section{TABLE}

THE HAEMODYNAMIC FINDINGS IN SEVERE AORTIC INCOMPETENCE AND IN MITRAL INCOMPETENCE

\begin{tabular}{|c|c|c|c|c|c|}
\hline Diagnosis & & Arterial D & ilution Curve & & rdiac \\
\hline & $\begin{array}{l}\text { Area } \\
\left(\mathrm{cm} .{ }^{2}\right)\end{array}$ & $C L C R^{*}$ & $\begin{array}{l}\text { Gradient } \\
\text { of the } \\
\text { Down-slope }\end{array}$ & $\begin{array}{l}\text { tion } \\
\text { Time } \\
\text { (sec.) }\end{array}$ & $\begin{array}{l}\text { (l. } \\
\min .)\end{array}$ \\
\hline
\end{tabular}

\section{Severe aortic} incompetence without heart failure

Slight mitral incompetence

Severe aortic incompetence with heart failure

Severe mitral incompetence 53
$(39-63)$
53 $0 \cdot 7$ $(0 \cdot 6-0 \cdot 8)$ 0.7 $0 \cdot 15$

Figures indicating the range of the results are shown in parenthesis. 

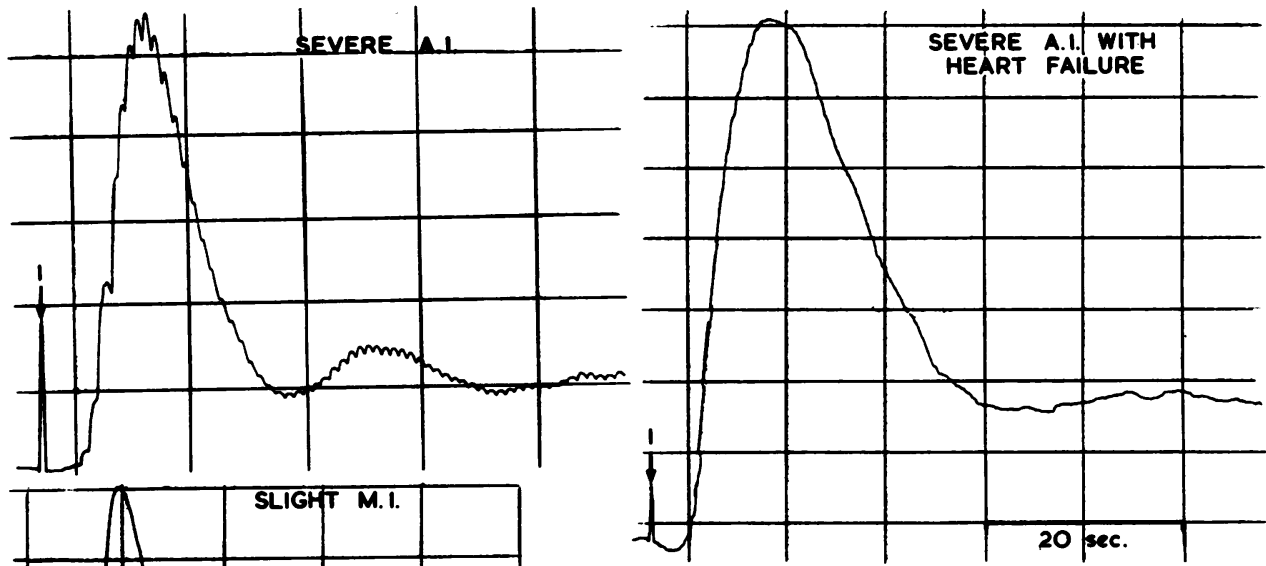

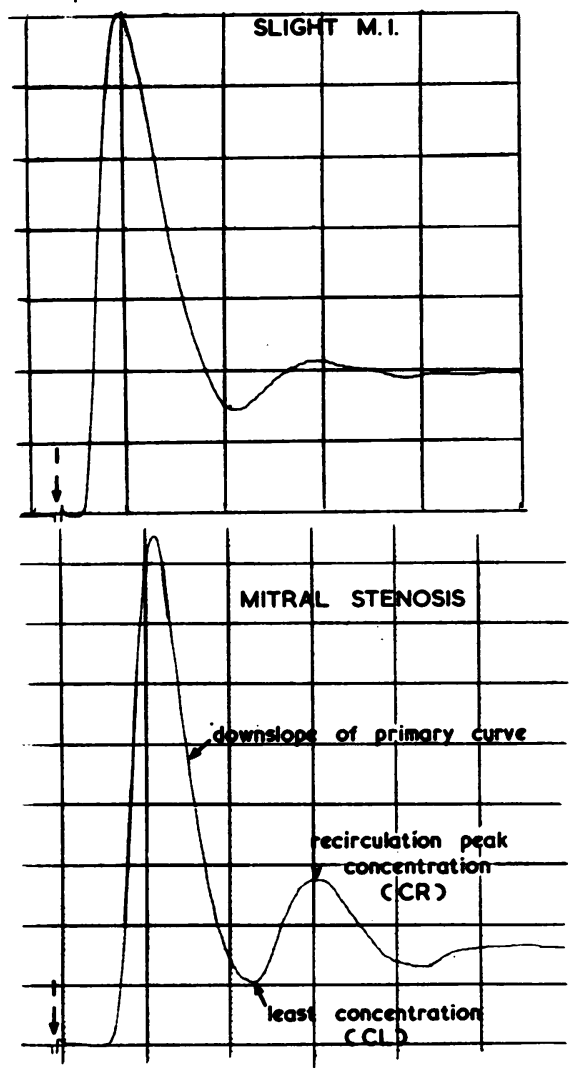

25 and $35 \mathrm{~mm}$. $\mathrm{Hg}$, and the left ventricular and diastolic pressures between 0 and $14 \mathrm{~mm}$. $\mathrm{Hg}$ above the sternal angle, except in the patient with congestive heart failure where the values were 65 and $30 \mathrm{~mm}$. $\mathbf{H g}$.

The results of the examination of the arterial dilution curves and the estimates of the left atrial size are shown in the Table, together with the calculations from the published (Nixon and Snow, 1962) cases of mitral incompetence.
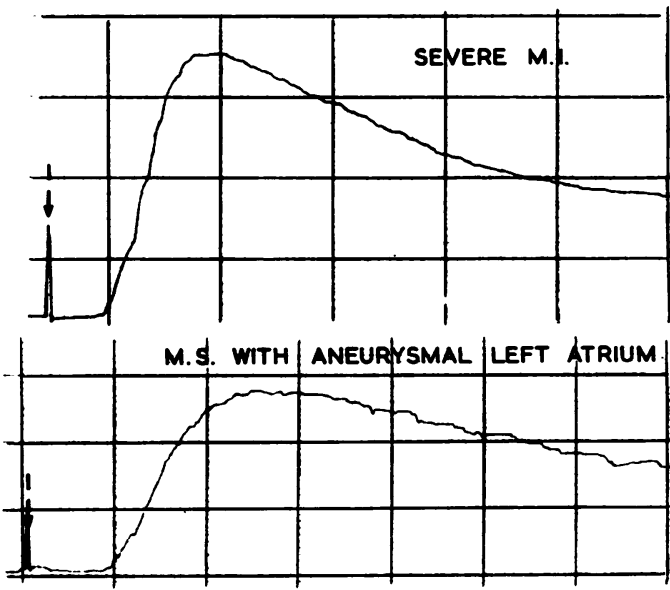

A.I. = Aortic Incompetence M.I. = Mitrol Incompetence

Ear-piece indicator-dilution curves in valvular heart disease. I marks the time of the bzginning of the injection of blue dye into the left atrium.

The Figure shows the dilution curve from one of the patients with severe aortic regurgitation, and from the patient with severe aortic regurgitation and congestive failure ; curves from patients with mitral disease are illustrated for comparison.

\section{Discussion}

These results suggest that the arterial dilution curve abnormality caused by severe aortic regurgitation without heart failure is similar in 
degree to the abnormality found in patients with slight mitral incompetence when the disability is minimal and the pulmonary arterial pressure normal ; and much less than that which occurs in severe mitral regurgitation where the mitral orifice measures $3.0 \mathrm{~cm}$. or more.

This series is small, and it is possible that the patients selected for their severe aortic regurgitation had less advanced disease than the patients with severe mitral incompetence, but the degree of disability suggests that this explanation is unlikely to be correct. Although the series is small, the differences between the two diseases are consistent, and they are wide enough to raise the question of a fundamental difference in haemodynamics. Since the shape of the dilution curve depends on the volume of blood with which the injected dye mixes, and on the time that is required for the mixture of blood and dye to leave the heart, it follows that it is differences in mixing, heart volumes, and circulation times which must be responsible for differences in dilution curve patterns.

There is no reason to suppose that mixing from turbulence is much greater in severe mitral incompetence than it is in severe aortic incompetence.

It is possible that the regurgitant volume of severe mitral incompetence is much greater, for a given degree of disability, than the regurgitant volume of severe aortic incompetence. However, the Braunwald test showed that the amount of blood regurgitated in our cases of aortic incompetence probably exceeded the contents of the thoracic aorta, and it is difficult to imagine that it could be very much larger in mitral incompetence.

The residual volumes of the heart appear to have a great influence on the shape of the indicator-dilution curve. When the residual volume of a chamber is small, a large volume must be regurgitated into it before the down-slope of the dilution curve is slowed (Emanuel, Lacy, and Newman, 1959) ; and enlargement of the residual volume increases the distortion of the dilution curve by increasing the amount of blood exposed to mixing with the regurgitated indicator (Levinson, Carleton, and Abelmann, 1959). In mitral stenosis with aneurysmal dilatation of the left atrium the residual volume of the left atrium is greatly increased, and the dye curve is severely distorted (Figure) in the absence of any appreciable regurgitation (Nixon and Snow, 1962 ; Nixon and Ikram, 1963). It is quite likely that a smaller residual volume is contained in the active left ventricle of severe aortic incompetence without failure than in the fibrillating left atrium of severe mitral incompetence, and it is to be expected that the residual volume and the dilution curve distortion will increase in aortic incompetence when heart failure supervenes. The time required for blood to flow through vascular chambers depends on the rate of flow and the volume of the system. In severe aortic incompetence without failure and in slight mitral incompetence the forward cardiac output and the mean circulation time values were similar, and it probably follows that the residual volumes in the two conditions also were similar. The prolongation of the mean circulation time in aortic incompetence with failure and in severe mitral incompetence, when the cardiac outputs were similarly reduced, probably indicates an increase of similar magnitude in the residual volume of the chambers receiving the regurgitated blood.

In this study it was found that the left atrial sizes and the dilution curve characteristics were similar in severe aortic regurgitation without failure and in slight mitral incompetence. Furthermore, in the patient with aortic regurgitation and heart failure the size of the left atrium and the distortion of the dilution curve both approached those of severe mitral incompetence. The left atrium was the first mixing chamber to be traversed by the dye, and at first sight it appears possible that its volume determines the shape of the dilution curve in aortic incompetence. It seems more likely, however, that the enlargement of the left atrium and the distortion of the dilution curve both result from the increased volume of the left ventricle, and are not directly related to each other.

In some cases of severe aortic regurgitation it is very difficult to be sure of the presence or the absence of severe mitral regurgitation, the presence of which may not even be suspected, and it is important to make the diagnosis before the patient reaches the operating theatre. From this study, and an experience of combined mitral and aortic incompetence, we believe that severe distortion of the dilution curve should be regarded as a sign of the mitral lesion in patients who are free from congestive heart failure.

\section{SUMMARY}

Arterial indicator-dilution curves were recorded after blue dye had been injected into the left atrium in patients with severe aortic incompetence and in patients with slight or severe mitral incompetence. The down-slopes of the dilution curves, the ratios of least concentration to recirculation 
peak concentration, the cardiac outputs, and the mean circulation times of severe aortic incompetence were similar to those of slight mitral incompetence, and only approached the gross disturbances of severe mitral incompetence in a patient with congestive heart failure. A similarity between the left heart's residual volume in severe aortic incompetence and slight mitral incompetence, and between aortic incompetence with failure and severe mitral incompetence, was thought to be the reason for the findings.

Gross distortion of the arterial indicator-dilution curve in a patient with severe aortic incompetence without heart failure should be attributed to coincidental mitral incompetence until that lesion has been excluded.

The authors are deeply indebted to Mr. G. H. Wooler and to Professor R. E. Tunbridge for making this study possible. They are grateful to Miss V. Tuke and to Mrs. M. Williams for assistance. The Board of Governors of the United Leeds Hospitals and private benefactors have provided financial assistance. The salary of one of us (H.M.S.) is paid by the Trustees of the Nuffield Foundation.

\section{REFERENCES}

Braunwald, E., and Morrow, A. G. (1958). A method for the detection and estimation of aortic regurgitant flow in man. Circulation, $17,505$.

Emanuel, R. W., Lacy, W. W., and Newman, E. V. (1959). Relative effects of heart chambers, lungs, and mitral insufficiency on the shape of indicator dilution curves. Circulat. Res., 7, 141.

Korner, P. I., and Shillingford, J. P. (1955). The quantitative estimation of valvular incompetence by dye dilution curves. Clin. Sci. $14,553$.

Levinson. G. E., Carleton, R. A., and Abelmann, W. H. (1959). Assessment of mitral regurgitation by indicator dilution: an analysis of the determinants of the abnormal dilution curve. Amer. Heart J., 58, 873.

Nixon, P. G. F. (1960). The transeptal approach to the left atrium in mitral regurgitation. Thorax, 15, 225.

and Snow, H. M. (1962). Indicator dilution curves in mitral valvular disease. Brit. Heart J., $24,637$.

- and Ikram H. (1963). The diagnosis of the mitral lesion in patients with giant left atria. Thorax, 18, 307.

Phinney, A. O., Cotton, K., and Shillingford, J. P. (1961). Mixing and indicator dilution curves. Clin. Sci., $20,75$.

Wood, E. H., and Woodward, E. (1957). A simple method for differentiating mitral regurgitation from mitral stenosis by means of indicator dilution curves. Proc. Mayo Clin., 32, 536.

Woodward, E., Burchell, H. B., and Wood, E. H. (1957). Dilution curves associated with valvular regurgitation. Ibid., 32, 518. 